\title{
Effects of Beeswax Coating on the Oxidative Stability of Long-Ripened Italian Salami
}

\author{
Marcello Trevisani, Matilde Cecchini, Daniela Siconolfi, \\ Rocco Mancusi, and Roberto Rosmini \\ Department of Veterinary Public Health and Animal Pathology, University of Bologna, Bologna, Italy \\ Correspondence should be addressed to Marcello Trevisani; marcello.trevisani@unibo.it
}

Received 29 November 2016; Accepted 18 January 2017; Published 1 February 2017

Academic Editor: Marta Laranjo

Copyright (C) 2017 Marcello Trevisani et al. This is an open access article distributed under the Creative Commons Attribution License, which permits unrestricted use, distribution, and reproduction in any medium, provided the original work is properly cited.

\begin{abstract}
Beeswax coating of foods put a barrier to oxygen, light, and vapour that can help to prevent oxidation of fat and pigments and water loss. The amounts of 2-thiobarbituric acid reactive substances (TBARS) and water activity (Aw) were assessed in Italian salami coated with beeswax at 55 days of ripening and compared with controls at 5, 6, and 7 months of shelf life. The results were correlated with sensory quality. TBARS levels were below $0.8 \mathrm{mg} \mathrm{kg}^{-1}$ in the beeswax-coated salami until 6 months of aging (median 0.697 , max 0.795 ) and significantly higher in the uncoated salami (median 1.176, max 1.227). A slight correlation between the amount of TBARS and Aw was observed in beeswax-coated salamis, whereas this effect was masked in controls by the large Aw variability observed at 7 months. Beeswax coating prevents case hardening and facilitated the peeling.
\end{abstract}

\section{Introduction}

Beeswax is natural glazing agent that can be used in food to prevent water loss and provide protection during storage. It is often used to prevent water loss and retard shrinkage and spoilage in fruit and cheese. Refined beeswax coating is a natural alternative to plastic envelopes that does not harm the environment and meets the criteria for GRAS status defined by the FDA for food packaging materials [1]. It is approved for food use in most countries and in the European Union under the E number "E901" [2]. Colour changes occur due to oxidation phenomena involving myoglobin during ripening of salami. Moreover, shrinkage due to dehydration results in aspect modifications, mainly ascribable to fat aggregation [3]. Even after salami has reached water activity $(\mathrm{Aw})$ and $\mathrm{pH}$ values that make the product shelf stable without refrigeration, environmental conditions for storage (relative humidity, relative air speed, temperature, and light) need to be controlled to prevent excessive water loss, product shrinkage and too hard consistency, oxidative changes, and excessive growth of moulds. During distribution salami is often wrapped in plastic film with reduced oxygen and water vapour permeability to prevent contamination by dirt and off-odour and protect the products from oxygen and loss or uptake of moisture. Oxygen moisture barrier properties of beeswax are intermediate between low and high density polyethylene [4]. It is also a barrier to photooxidation. Beeswax is also one of the most effective materials employed to decrease water vapour permeability of edible films due to its high hydrophobicity and solid state at room temperature $[5,6]$. These properties have been used to preserve and improve the sensorial quality of salami during aging. Local producers in the area of Bologna (Italy) used to coat salami with beeswax, after the products are shelf stable (i.e., water activity has decreased to values below 0.92 ). They use the natural beeswax to limit an excessive water loss during storage. Wax coating also prevents case hardening and mould development and made the peelability easy. This study was aimed at assessing the oxidative stability and sensorial characteristics of salami after beeswax coating.

\section{Materials and Methods}

2.1. Reagents. The reagents were as follows: trichloroacetic acid (TCA) 99\%; 1,1,3,3-tetramethoxypropane (TMP) 99\%; 
2-thiobarbituric acid (TBA) 98\% (Sigma-Aldrich, Italy); ethylenediaminetetraacetic acid disodium salt (EDTA) (AnalR ${ }^{\circledR}$ VWR); propyl gallate (Fluka); hydrochloridric acid $37 \%$ (Merck); sodium hydroxide 20\% water solution (Carlo Erba, Italy); TCA $100 \%$ p/v (100 g TCA 99\%, water up to $100 \mathrm{~mL}$ ); TMP stock solution (1000 $\left.\mathrm{mg} \mathrm{kg}^{-1}\right)$; extracting solution (75 mL TCA 100\%, $20.8 \mathrm{~mL} \mathrm{HCl} 0.25 \mathrm{M}, 1 \mathrm{~g}$ EDTA, $1 \mathrm{~g}$ propyl gallate, and water up to $1000 \mathrm{~mL}$ ); TBA reagent (TBA $80 \mathrm{mM}$ in in $\mathrm{NaOH} 1 \mathrm{M}, \mathrm{pH}$ corrected at 4.0-4.2 with $\mathrm{HCl} 1 \mathrm{M})$; TMP (5 $\left.\mathrm{mg} \mathrm{kg}^{-1}\right)$ working solution $(250 \mu \mathrm{L} \mathrm{TMP}$ stock solution, $3.75 \mathrm{~mL}$ TCA $100 \%$, and $\mathrm{HCl} 0.25 \mathrm{M}$ up to $50 \mathrm{~mL})$.

2.2. Samples. Twelve salamis "Felino IGP" were provided by a local producer at approximately 55 days of ripening. The salamis had the typical characteristics (length $40-45 \mathrm{~cm}$, diameter approximately $6 \mathrm{~cm}$, weight $1.0-1.2 \mathrm{Kg}$, weight loss $35-37.5 \%$, and water activity $0.90-0.92$ ). The salamis derived from a single lot were divided into two groups. Six were used as control. The remaining were brushed, washed, and put back to dry in ventilated cells. Then they were wrapped in a cotton gauze and tied and covered with beeswax (yellow organic beeswax melted and held at $62-64^{\circ} \mathrm{C}$ ) for $3-5 \mathrm{sec}-$ onds. The resulting wax layer had a thickness of $2-3 \mathrm{~mm}$. Therefore, all salamis were hang up to dry in well-aired cellars up to 5-7 months, packed in cartoons, and stored in a dark room at $5^{\circ} \mathrm{C} \pm 1^{\circ} \mathrm{C}$ (relative humidity $85-90 \%$ ) until analyses. Comparative assessments were made on two salamis for each treatment group (wax coated and uncoated) at 5, 6, and 7 months.

2.3. Quantification of TBARS. Three slices ( $5 \mathrm{~mm}$ thick) were taken from centre and intermediate parts from each salami. These samples were minced for 10 seconds with a Moulinette $^{\circledR}$ and $2.5 \mathrm{~g}$ of the homogenate was analysed for 2-Thiobarbituric Acid Reactive Substances (TBARS) using the method developed by Wang et al. [7] for meat and meat products. The entire protocol (sampling and analyses) was repeated two times (i.e., after 2-3 days) using other portions of each salami. A total of eight measurements (2 salamis, 2 replicates, and 2 repetitions) for each treatment group and storage time were obtained. Sample homogenates were put in vials in an ice bath, mixed with $20 \mathrm{~mL}$ of chilled extracting solution, and homogenised at 16,000 rpm for 2 minutes with Ultra-turrax $^{\circledR}$ (model T25 basic IKA, Labortechnic, Italy). Additional $5 \mathrm{~mL}$ of extracting solution was used to wash the blades of the Ultra-turrax (final dilution 1:10); then the extracted samples were filtered (Whatman ${ }^{\circledR}$ paper filter n.4). Samples were continuously maintained in a chilled bath until the filtration. Two $\mathrm{mL}$ of the filtrates was mixed with $2 \mathrm{~mL}$ of the TBA reagent and incubated at $40^{\circ} \mathrm{C}$ in a water bath for 90 minutes and then chilled in fridge at $6-8^{\circ} \mathrm{C}$ for 30 minutes. Therefore the absorbance at $532 \mathrm{~nm}$ was read (5 replicates) on a spectrophotometer (Perkin-Elmer, model Lambda 1). A calibration curve was designed using standards at concentration in the range of 0.025 to $0.7 \mathrm{mg} \mathrm{mL}^{-1}$ of TMP $\left(5 \mathrm{mg} \mathrm{kg}^{-1}\right)$ working solution. By using the above-mentioned TMP solutions, malondialdehyde (MDA) standards in the range of 0.15 to $4.26 \mathrm{nmol} \mathrm{mL}^{-1}$ were prepared. Nine TMP standards (from 20 to $560 \mu \mathrm{L}$ of the TMP working solution) were mixed with $2 \mathrm{~mL}$ of TBA reagent, $300 \mu \mathrm{L}$ of TCA $100 \%$, and $\mathrm{HCl} 0.25 \mathrm{M}$ up to $4 \mathrm{~mL}$. A blank solution was made as described before, but without TMP. Vials with the TMP standards and blank were incubated as described for the samples and the absorbance values at $532 \mathrm{~nm}\left(\mathrm{Abs}_{532}\right)$ were read (average of 5 replicates). Ten-point standard calibration curves were designed. The coefficient $\mathrm{R}^{2}$ must be between 0.995 and 1 in order to accept the curves for TBARS quantification. The samples' TBARS concentration was calculated by interpolation of their measured absorbance values (Abs). The resulting value was multiplied by the dilution factor of the sample $(2.5 \mathrm{~g}$ in $25 \mathrm{~mL})$ and extract $(1: 2)$ to correct for the final concentration. Results are expressed as $\mathrm{mg} \mathrm{kg}^{-1}$ of MDA equivalents TBARS.

2.4. Water Activity. The water activity (Aw) was assessed with a dew point water activity meter (Aqualab Series 3, Decagon, US) using the procedures recommended by the producer.

2.5. Sensory Test. A hedonic test was conducted with eight untrained assessors who scored the acceptability of 3 attributes (texture, taste, and flavour) using the following 1-10 point scale: texture $(1=$ hard; $10=$ soft $)$; presence of acid taste $(1=$ sharp burning; 10 = mild acidic); rancid off-flavour ( 1 = none; $3=$ slightly perceived; $10=$ strong). With this aim, the salamis analysed for the TBARS at 6 and 7 months of storage were cut in slices and the panel was asked to comparatively assess the quality of the salami (blind test between beeswax-coated or noncoated salami).

2.6. Statistical Analysis. TBARs values recorded for different categories (wax or not coating) and periods $(0,1$, and 2 months of storage) were summarized graphically as box and whiskers plots. Statistical analyses were performed using the R package "stats" (version 2.15.3) [8]. Data relative to samples from different categories and period were analysed with Bartlett's test to assess homoscedasticity (homogeneity of variance). When departures from normality of data were observed nonparametric alternatives to the analysis of variance (ANOVA) were used. In particular, the Wilcoxon signed-rank test was used for comparing the MDA equivalent TBARS values observed in salami packaged with or without wax. Differences among samples taken at 5, 6, and 7 months were analysed with the Kruskal-Wallis rank sum test. When differences were considered to be significant at $p \leq 0.01$ the significance of individual pair differences (aging periods) was tested for inequality using the multiple comparison test after Kruskal-Wallis using the R package "pgirmess."

\section{Results and Discussion}

3.1. Effect of the Beeswax Coating on the TBARS Concentration. Slower drying and ripening at low temperatures of the beeswax-coated salami resulted in less lipid oxidative changes. The concentration of TBARS (MDA equivalents) is reported in Table 1 . Values were below $0.8 \mathrm{mg} \mathrm{kg}^{-1}$ in 
TABLE 1: TBARS concentrations in salami according to aging period and beeswax coating.

\begin{tabular}{|c|c|c|c|c|c|}
\hline \multirow{2}{*}{$\begin{array}{l}\text { Ageing } \\
\text { (months) }\end{array}$} & \multirow{2}{*}{ Coating } & \multicolumn{3}{|c|}{ TBARS (MDA mg kg-1) } & \multirow{2}{*}{ Wilcoxon $^{1}$ signed-rank test } \\
\hline & & Mean $^{2}$ & Median & Range & \\
\hline \multirow{2}{*}{5} & Beeswax & $0.693^{\mathrm{a}}( \pm 0.017)$ & 0.696 & $0.653-0.713$ & \multirow{2}{*}{$p=0.0039$} \\
\hline & Control & $1.016^{\mathrm{b}}( \pm 0.045)$ & 1.029 & $0.938-1.059$ & \\
\hline \multirow{2}{*}{6} & Beeswax & $0.678^{\mathrm{a}}( \pm 0.075)$ & 0.697 & $0.561-0.795$ & \multirow{2}{*}{$p=0.0039$} \\
\hline & Control & $1.166^{c}( \pm 0.045)$ & 1.176 & $1.104-1.227$ & \\
\hline \multirow{2}{*}{7} & Beeswax & $1.106^{\mathrm{b}}( \pm 0.039)$ & 1.098 & $1.048-1.173$ & \multirow{2}{*}{$p=0.0039$} \\
\hline & Control & $1.869^{\mathrm{d}}( \pm 0.023)$ & 1.872 & $1.819-1.897$ & \\
\hline
\end{tabular}

Note: mean, median, and range calculated from $n=8$ measurements (i.e., 2 samples, 2 replicates, and 2 repetitions for each treatment group). Samples with significant differences in their malondialdehyde level are indicated by different letters; ${ }^{1}$ significant differences detected between samples at the same aging period (Wilcoxon test).

${ }^{2}$ Significant differences detected between samples at different aging period (Kruskal-Wallis test) chi-square $=15.3934 ; p$ value $=0.0004543$.

the beeswax-coated salami until 6 months of aging (median 0.697 , max 0.795) and significantly higher in the uncoated salami (median 1.176, max 1.227). At 7 months the MDA median values were equal to 1.098 and $1.872 \mathrm{mg} \mathrm{kg}^{-1}$ in wax coated and uncoated salami, respectively. Limits for TBARS (MDA equivalents) have been suggested at $0.5 \mathrm{mg} \mathrm{kg}^{-1}$ of meat for threshold of consumer detection of rancidity [9-11] and $1.0 \mathrm{mg} \mathrm{kg}^{-1}$ for sausage products [12]. However, detection limits have not been set for salami. The lipid peroxidation in raw ripened sausages (salami) involves transformation of primary products of lipid degradation (alkyl free radical with a group of conjugated bonds) into secondary products, including MDA [13-15], and this is correlated to the increase of TBARS concentration. The presence of high TBARS values in sausages after ripening can be explained by availability of oxygen consequently to the mechanical process [16]. However, the use of vacuum stuffing, antioxidants, the protective effect of some starters [17], and also the storage of ripening sausage in vacuum or modified atmosphere without oxygen [18] can significantly contribute to an increased oxidative stability. The latter condition can occur with the use of beeswax coating. In a study of Novelli et al. [19] concerning "Milano" salami with similar fat content (approximately $30 \%$ ), the TBARS values were equal to $1.39 \pm 1.08 \mathrm{mg}$ MDA $\mathrm{kg}^{-1}$ at $>3$ months of aging, which is a value higher than those of the beeswax-coated salami at 7 months of aging.

Even if the consumers do not perceive any flavour deterioration, lipids oxidation involves loss of unsaturated fatty acids (nutrient loss) and the end products of lipid oxidation may be mutagenic and carcinogenic. Malondialdehyde (MDA) can react with DNA and form MDA adducts [20, 21]. Storage of ripening sausage in vacuum or modified atmosphere has resulted in increased oxidative stability of raw sausage after 2 and 5 months of storage [18]. Beeswax coating appears to give similar protection.

3.2. Correlation between TBARS Concentration, Aw, and Sensory Evaluations. The beeswax-coated salami had significantly higher mean Aw values, from 0.903 to 0.888 , between 5 and 7 months of aging. The uncoated salami had Aw values in a range of 0.812 to 0.821 (Table 2). The sensory test did not reveal relevant differences in the taste and flavour of different
TABLE 2: Changes in the water activity values $(\mathrm{Aw})$ in salamis with or without beeswax coating.

\begin{tabular}{lcc}
\hline Ageing period & Control & Beeswax coating \\
\hline 5 months & $0.821 \pm 0.001^{\mathrm{a}}$ & $0.903 \pm 0.002^{\mathrm{c}}$ \\
6 months & $0.812 \pm 0.002^{\mathrm{a}}$ & $0.899 \pm 0.002^{\mathrm{d}}$ \\
7 months & $0.820 \pm 0.011^{\mathrm{a}}$ & $0.888 \pm 0.004^{\mathrm{e}}$ \\
\hline
\end{tabular}

Aging period at the beginning of the shelf life $=5$ months.

Differences related to coating: $\mathrm{F}$ calculated $=1192.81 ; \mathrm{F}$ critical $=4.75 ; p$ value $=2.21 * 10^{-13}$.

Differences related to aging (in salami with beeswax coating): $\mathrm{F}$ calculated $=$ 23.03; $\mathrm{F}$ critical $=5.14 ; p$ value $=0.0015$.

Means with different letters are significantly different.

treatment groups, whereas texture was softer in the beeswaxcoated salami (Figure 1). The softer texture was related to the lower loss of water. There is a statistically significant relationship between TBARS and Aw values, but only for the beeswax-coated salami (Spearman's rank correlation rho $=$ $-0.623 ; p$ value $=0.0011)$. Within this group the concentration of TBARS slightly increased in consequence of the water loss, but this effect was masked in controls by the large Aw variability observed at 7 months $(\mathrm{Aw}=0.820 \pm 0.011$; range 0.814-0.832) (Table 2 and Figure 2). Any difference was perceived during the sensory test with regard to sharp burning taste (Wilcoxon paired sign test $p$ value $>0.05$ ). Also the presence of rancid off-flavour was not perceived and only two panel members (out of eight) reported value above the limit of perception in the uncoated salami at 7 months of aging. The panel test probably did not give rise to a negative score (rancid off-flavour) because the TBARS concentration was relatively low (1.819-1.897 $\mathrm{mg} \mathrm{MDA} \mathrm{kg}^{-1}$ ) also in these samples. An unpleasant fruity flavour was perceived by some panel members in the salami coated with beeswax at 7 months of aging. This flavour deterioration might be related to spoilage by heterofermentative lactic acid bacteria in consequence of the higher Aw [22, 23]. There are no published studies available that define TBARS values that are associated with the presence of rancid off-flavours in "Felino" salami.

Šojić et al. [24] reported that vacuum and MAP packaging can contribute to better oxidative and sensory stability of 

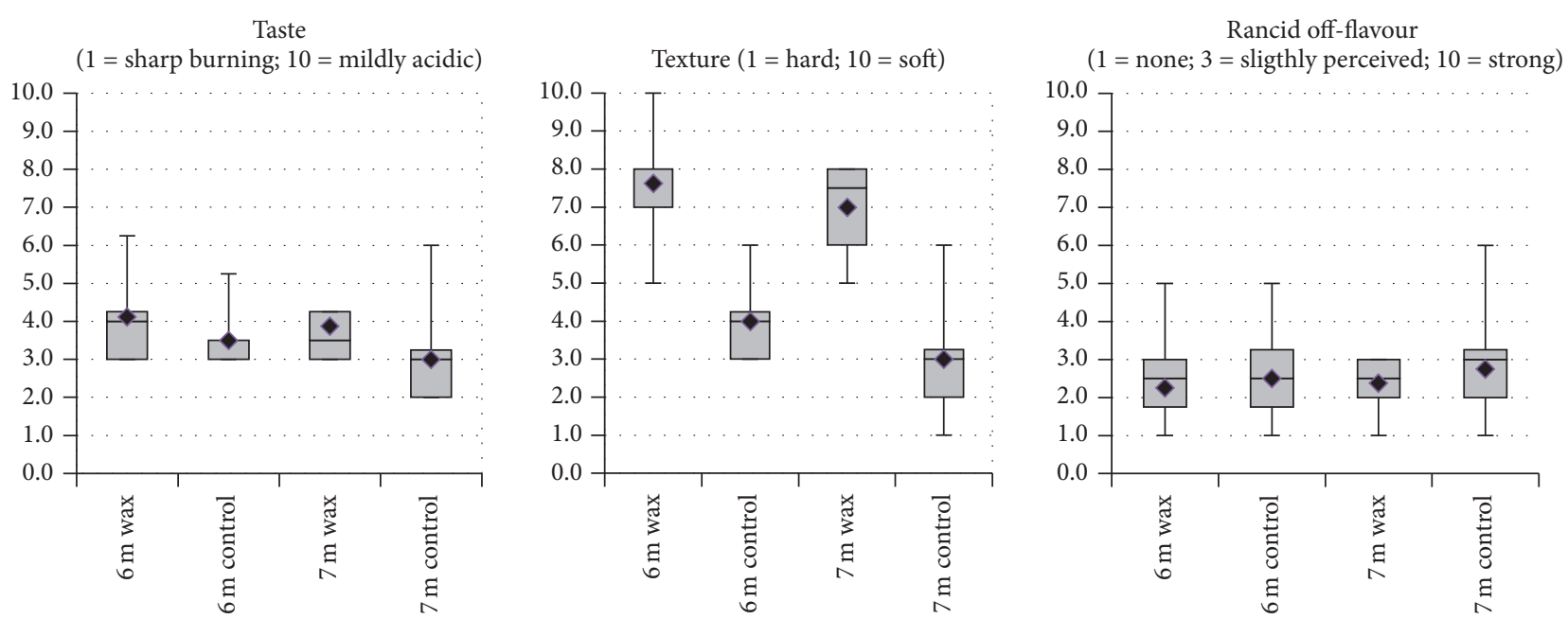

Figure 1: Box and whiskers plot for sensory quality of salami at 6 and 7 months of aging. Notes: box indicates quartiles and the central line the median. The lines ("whiskers") show the largest or the smallest observation. The symbol $\downarrow$ indicates average values.
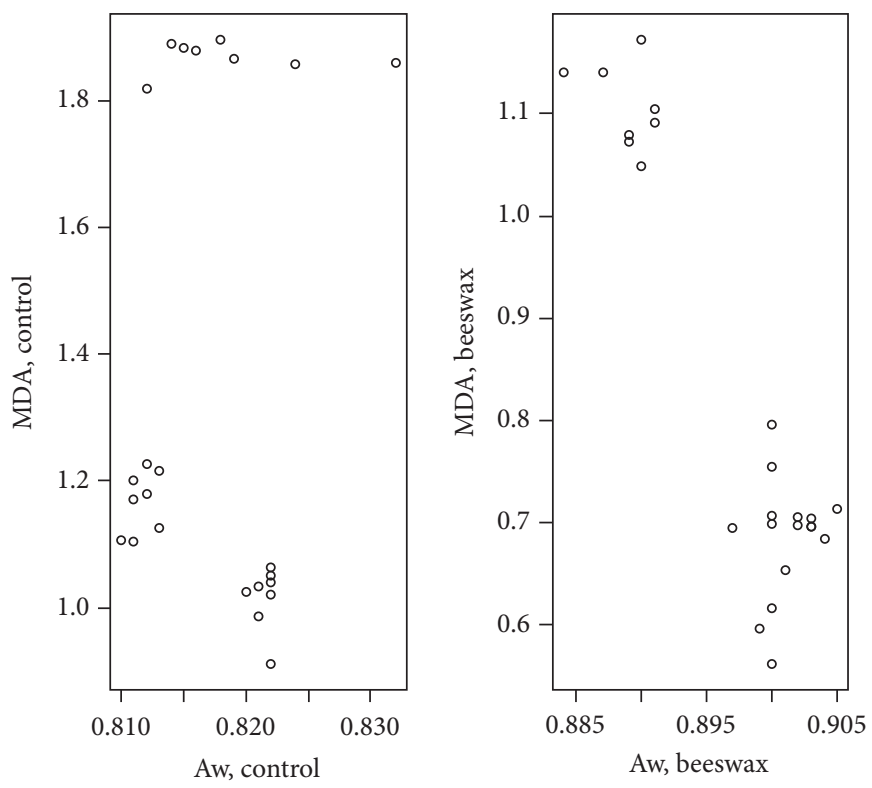

FIgURE 2: Relationship between TBARS and Aw values.

dry fermented sausage and that TBARS values are negatively correlated with odour and taste of salami aged for 7 months. Bañón et al. [25] observed that the main causes of loss of sensory quality of salami limiting their shelf life under the tested retail (aerobic) conditions include flavour deterioration associated with rancidity, bitterness, and mouldy offflavour, together with hardening and loss of juiciness.

\section{Conclusions}

The results of this preliminary study indicate that beeswax coating can be a useful alternative to the plastic packaging. This natural coating material can be used to increase the aging period without compromising the texture, which remains soft and is appreciated for its better flavour. Beeswax effectively reduces the development of lipid peroxidation products in these salamis.

\section{Additional Points}

Practical Applications. Beeswax coating can be used to preserve and improve the sensorial quality of salami during aging. It can be a natural packaging material that does not harm the environment and has good oxygen moisture barrier properties.

\section{Competing Interests}

The authors declare that there is no conflict of interests regarding the publication of this paper. 


\section{Acknowledgments}

This study was supported by the School of Specialization in Inspection of Food of Animal Origin of the University of Bologna, Italy.

\section{References}

[1] CFR (Code of Federal Regulations), Title 21, Chapter I, Part 582-substances generally recognized as safe. Section 582.1975-bleached beeswax, April 2013, GPO’s Federal Digital System, https://www.gpo.gov.

[2] European Commission, "Commission Regulation (EU) No 10/2011 of 14 January 2011 on plastic materials and articles intended to come into contact with food," Official Journal of the European Union L, vol. 12, pp. 1-89, 2011.

[3] L. Fongaro, C. Alamprese, and E. Casiraghi, "Ripening of salami: assessment of colour and aspect evolution using image analysis and multivariate image analysis," Meat Science, vol. 101, pp. 73-77, 2015.

[4] B. Cuq, N. Gontard, and S. Guilbert, "Edible films and coating as active layers," in ActiVe Food Packaging, M. L. Rooney, Ed., pp. 111-142, Blackie Academic and Professional, Glasgow, UK, 1995.

[5] V. Morillon, F. Debeaufort, G. Blond, M. Capelle, and A. Voilley, "Factors affecting the moisture permeability of lipidbased edible films: a review," Critical Reviews in Food Science and Nutrition, vol. 42, no. 1, pp. 67-89, 2002.

[6] L. Yang and A. T. Paulson, "Effects of lipids on mechanical and moisture barrier properties of edible gellan film," Food Research International, vol. 33, no. 7, pp. 571-578, 2000.

[7] B. Wang, R. D. Pace, A. P. Dessai, A. Bovell-Benjamin, and B. Phillips, "Modified extraction method for determining 2thiobarbituric acid values in meat with increased specificity and simplicity," Journal of Food Science, vol. 67, no. 8, pp. 2833-2836, 2002.

[8] R Core Team, R: A Language and Environment for Statistical Computing, R Foundation for Statistical Computing, Vienna, Austria, 2013, http://www.R-project.org/.

[9] J. I. Gray and A. M. Pearson, "Rancidity and warmed-over flavor," in Restructured Meat and Poultry Products, A. M. Pearson and T. R. Dutson, Eds., pp. 221-269, Van Nostrand Reinhold Co, New York, NY, USA, 1987.

[10] C. Severini, T. De Pilli, and A. Baiano, "Partial substitution of pork backfat with extra-virgin olive oil in 'salami' products: effects on chemical, physical and sensorial quality," Meat Science, vol. 64, no. 3, pp. 323-331, 2003.

[11] Y.-S. Choi, J.-H. Choi, D.-J. Han et al., "Effects of replacing pork back fat with vegetable oils and rice bran fiber on the quality of reduced-fat frankfurters," Meat Science, vol. 84, no. 3, pp. 557$563,2010$.

[12] J. G. Bloukas, E. D. Paneras, and G. C. Fournitzis, "Effect of replacing pork backfat with olive oil on processing and quality characteristics of fermented sausages," Meat Science, vol. 45, no. 2, pp. 133-144, 1997.

[13] P. A. Morrissey, P. J. A. Sheehy, K. Galvin, J. P. Kerry, and D. J. Buckley, "Lipid stability in meat and meat products," Meat Science, vol. 49, no. 1, pp. S73-S86, 1998.

[14] M. A. Fellenberg and H. Speisky, "Antioxidants: their effects on broiler oxidative stress and its meat oxidative stability," World's Poultry Science Journal, vol. 62, no. 1, pp. 53-70, 2006.
[15] K. M. Wójciak and Z. J. Dolatowski, “Oxidative stability of fermented meat products," ACTA Scientiarum Polonorum Technologia Alimentaria, vol. 11, no. 2, pp. 99-109, 2012.

[16] C. Summo, F. Caponio, and A. Pasqualone, "Effect of vacuumpackaging storage on the quality level of ripened sausages," Meat Science, vol. 74, no. 2, pp. 249-254, 2006.

[17] H. Bozkurt and O. Erkmen, "Effects of starter cultures and additives on the quality of Turkish style sausage (sucuk)," Meat Science, vol. 61, no. 2, pp. 149-156, 2002.

[18] I. Valencia, D. Ansorena, and I. Astiasarán, "Stability of linseed oil and antioxidants containing dry fermented sausages: a study of the lipid fraction during different storage conditions," Meat Science, vol. 73, no. 2, pp. 269-277, 2006.

[19] E. Novelli, E. Zanardi, G. P. Ghiretti et al., "Lipid and cholesterol oxidation in frozen stored pork, salame Milano and mortadella," Meat Science, vol. 48, no. 1-2, pp. 29-40, 1998.

[20] L. J. Marnett, "Lipid peroxidation-DNA damage by malondialdehyde," Mutation Research-Fundamental and Molecular Mechanisms of Mutagenesis, vol. 424, no. 1-2, pp. 83-95, 1999.

[21] L. J. Marnett, "Oxy radicals, lipid peroxidation and DNA damage," Toxicology, vol. 181-182, pp. 219-222, 2002.

[22] B. Ray, "Spoilage of specific food groups," in Fundamental Food Microbiology, pp. 213-232, CRC Press, Boca Raton, Fla, USA, 3rd edition, 2003.

[23] M. Trevisani and R. Rosmini, "Igiene e tecnologie dei prodotti carnei," in Igiene e Tecnologie Degli Alimenti di Origine Animale, G. Colavita, Ed., pp. 169-201, Le Point Vétérinaire Italie, Milano, Italy, 2012.

[24] B. Šojić, N. Hromiš, L. Petrović et al., "Effect of packaging method and storage period on fatty acid profile and TBARS value of traditional sausage (Petrovskà Klobàsa)," Journal on Processing and Energy in Agriculture, vol. 19, pp. 105-107, 2015.

[25] S. Bañón, R. Serrano, and M. Bedia, "Factors limiting the shelflife of salami pieces kept in retailing conditions," Italian Journal of Food Science, vol. 26, no. 3, pp. 289-299, 2014. 

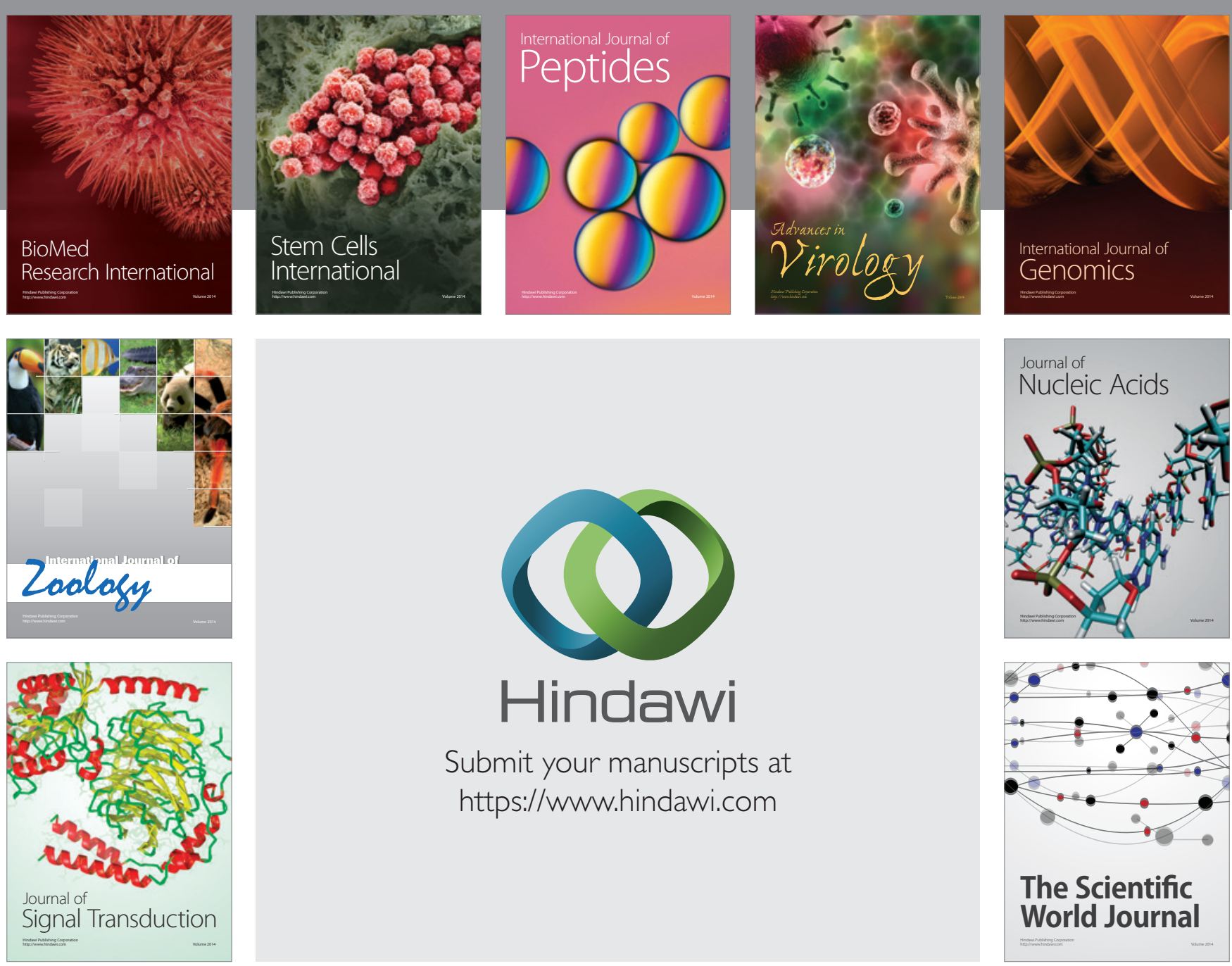

Submit your manuscripts at

https://www.hindawi.com
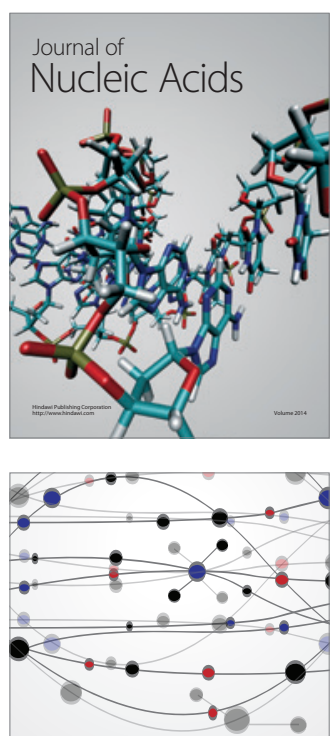

The Scientific World Journal
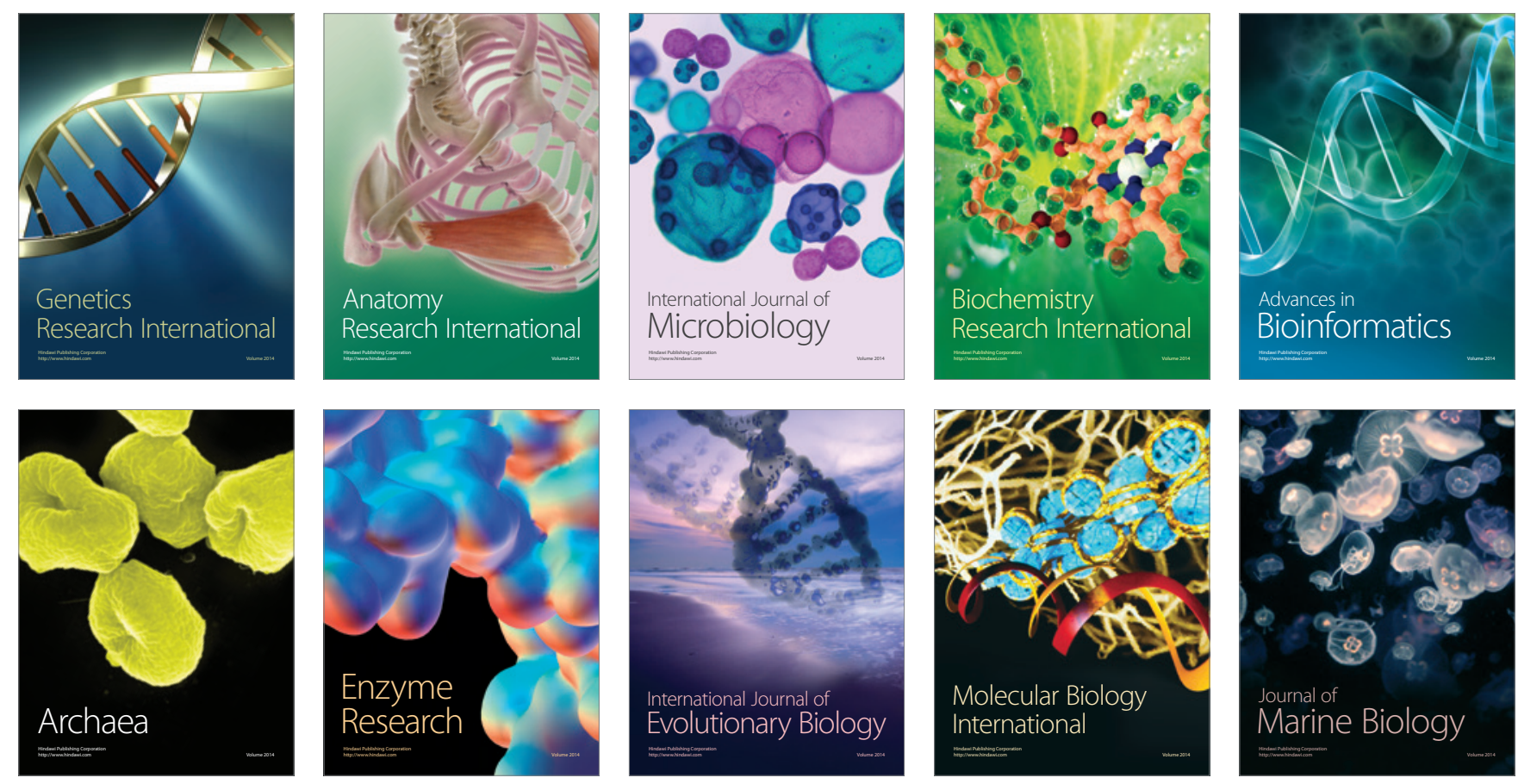